\title{
Factors playing role in heat acclimation processes in barley and oat plants
}

\author{
É. DARKÓ*, R. KHALIL ${ }^{* *}$, N. ELSAYED**, M. PÁL*, K.Á. HAMOW*,***, G. SZALAI*, J. TAJTI*, \\ Q.T. NGUYEN", N.T. NGUYEN", V.N. LE", and T. JANDA*,+
}

Department of Plant Physiology, Agricultural Institute, Centre for Agricultural Research, Hungarian Academy of Sciences, 2462 Martonvásár, Hungary*

Botany Department, Faculty of Science, Benha University, 13518 Benha, Egypt**

Plant Protection Institute, Centre for Agricultural Research of the Hungarian Academy of Sciences, Budapest, Hungary $^{* * *}$

Center for Research and Technology Transfer (CRETECH), Vietnam Academy of Sciences and Technology, Hanoi, Vietnam ${ }^{\#}$

\begin{abstract}
In the present study, the heat acclimation processes (growing at $30 / 27^{\circ} \mathrm{C}$ for 2 weeks) in spring and winter varieties of barley (Hordeum vulgare L., varieties 'Conchita' and 'Mv Initium') and oat (Avena sativa L., varieties 'Mv Pehely' and 'Mv Hópehely') were characterized. Temperature dependence of certain chlorophyll $a$ fluorescence induction parameters indicated the efficiency of heat acclimation. Heat treatment induced the activity of glutathinone-S-transferase, but decreased the amounts of the major polyamines. A significant increase in cadaverine content was found in 'Conchita'. 1,3-diaminopropane contents after heat acclimation were lower in the oat and higher in the barley varieties than that in the control plants. Salicylic acid and para-hydroxybenzoic acid contents were also induced at elevated temperatures. Changes in abscisic acid differed in the two species. Results suggest that besides certain similarities, different strategies can be activated to avoid the damaging effects of high temperatures in barley and oat plants.
\end{abstract}

Additional key words: hormone; oxidative stress; Poaceae; putrescine; reactive oxygen species; spermidine.

\section{Introduction}

Partly due to the global warming, heat injury is one of the most important abiotic stress factors limiting crop productivity in many regions of the world (Hernandez et al. 2018). Several plant species have evolved different mechanisms to acclimate to the increasing temperatures. However, rapid and extreme temperature rises often cause severe stress symptoms. This is especially true for those crop plants, which originate from far regions with different climate and have relatively narrow genetic diversity to cope with the fluctuating environment. Heat acclimation, which means exposure of plants to slightly elevated, nonlethal temperatures, may provide protection against a subsequent severe high temperature stress. Better understanding of physiological and molecular mechanisms of stress adaptation in cereals may provide useful information for breeders for developing new crops with better stress tolerance. The responses of plants to elevated temperatures involve several molecular mechanisms including the induction of signalling cascades, alteration of transcriptional control (Ohama et al. 2017), synthesis of osmoprotectants and heat shock proteins, or the induction of different mechanisms to prevent the overaccumulation of reactive oxygen species during severe heat stress (Volkov et al. 2006, Xu et al. 2006). The changes in the photosynthetic machinery upon exposure to elevated temperatures have also been extensively studied in various plant species (Allakhverdiev et al. 2008).

Exposure of plants to environmental stresses, including high temperatures, usually increase the production of reactive oxygenspecies(ROS). Livingorganisms, especially plants, where the avoidance mechanisms are less important than for animals, have evolved various enzymatic and nonenzymatic detoxification mechanisms to regulate ROS concentrations (Tripathy and Oelmüller 2012). Polyamines are cationic compounds that play a critical role in the development of plants (Tiburcio et al. 2014). Increased

$\overline{\text { Received } 15 \text { July } 2019}$, accepted 16 August 2019.

${ }^{+}$Corresponding author; phone: +36 22 569509, fax: +36 22569 576, e-mail: janda.tibor@agrar.mta.hu

Abbreviations: ABA - abscisic acid; APX - ascorbate peroxidase; DAP - 1,3-diaminopropane; $\mathrm{F}_{\mathrm{v}} / \mathrm{F}_{\mathrm{m}}$ - maximum photochemical quantum yield; G-POD - guaiacol peroxidase; GR - glutathione reductase; GST - glutathione-S-transferase; HA - heat acclimated; IAA - indole-3-acetic acid; $p$ HBA - para-hydroxybenzoic acid; PUT - putrescine; ROS - reactive oxygen species; SA - salicylic acid; SPAD - soil-plant analysis development; SPD - spermidine; SPM - spermine; $Y_{(I I)}-$ quantum yield of PSII; $Y_{(N O)}-$ nonregulated nonphotochemical quenching; $\mathrm{Y}_{(\mathrm{NPQ})}$ - regulated nonphotochemical quenching.

Acknowledgements: This research was supported by the Hungarian Government and the European Union, with the co-funding of the European Regional Development Fund in the frame of Széchenyi 2020 Program GINOP-2.3.2-15-2016-00029. The study was also supported by the Fund of the Cooperation Project between Vietnam Academy of Science and Technology and Hungarian Academy of Sciences (QTHU01.02/18-19). 
stress tolerance of plants was often associated with the increased polyamine contents. However, recent results also showed that the more polyamine the better is not generally valid (Pál et al. 2018, 2019). Directly or indirectly, partly via the polyamine cycle, they also take part in the stresssignalling pathways (Pál et al. 2015), scavenging of ROS (Mostofa et al. 2014) and, among others, stabilization of the photosynthetic apparatus (Hu et al. 2014). ROS regulatory systems and other signalling mechanisms need to be strictly coordinated in plants depending on the different growth stages and tissues for the appropriate responses to heat stress (Suzuki and Katano 2018). Using mutants deficient in different signals has demonstrated the significance of various pathways such as ROS regulatory systems and hormone signalling including processes related to abscisic acid (ABA), or salicylic acid (SA), in the heat responses of Arabidopsis plants (Larkindale et al. 2005). Although the responses of plants to elevated temperatures have been widely studied, the mechanisms of heat acclimation processes especially in monocot cereal species are much less understood.

We have recently demonstrated that growing at $30^{\circ} \mathrm{C}$ may provide protection against a subsequent heat stress in young wheat plants (Végh et al. 2018). The aim of the present study was to better understand the heat acclimation processes in other cereal species, barley and oat. First, we demonstrated that - similarly to young wheat plants growing at $30^{\circ} \mathrm{C}$ also has an acclamatory effect in these species. Then, we investigated the possible involvement of various stress-related mechanisms, such as antioxidant activities, polyamine metabolism, and the changes in certain plant growth regulators in control and heatacclimated plants.

\section{Materials and methods}

Plant materials and growth conditions: Two barley (Hordeum vulgare L.) cvs. 'Conchita' (spring variant) and 'Mv Initium' (winter type) and two oat (Avena sativa L.) cvs. 'Mv Pehely' (spring type) and 'Mv Hópehely' (winter type) were used in the experiments. These varieties were grown in pots filled with 3:1 (v:v) mixture of loamy soil and sand in a Conviron PGV-15 growth chamber (Controlled Environments Ltd., Winnipeg, Canada) at $22 / 20^{\circ} \mathrm{C}$ day/night temperature with $16 / 8$-h photoperiod at PPFD of $250 \mu \mathrm{mol} \mathrm{m} \mathrm{m}^{-2} \mathrm{~s}^{-1}$ at the canopy level, at $75 \%$ relative humidity. After $10 \mathrm{~d}$, a part of the plants was exposed to elevated temperatures at $30 / 27^{\circ} \mathrm{C}$ day/night temperature, while others were grown at $22 / 20^{\circ} \mathrm{C}$ (controls) for $14 \mathrm{~d}$. Samples were taken and measurements were carried out at the end of the heat-treatment period.

Estimation of chlorophyll (Chl) content and Chl a fluorescence induction measurements: Chl contents were estimated in the $3^{\text {rd }}$ fully developed leaves using a SPAD-502 chlorophyll meter (Konica-Minolta, Osaka, Japan). Chl $a$ fluorescence was measured with a pulse amplitude modulated fluorometer (Imaging-PAM M-series, Walz, Effeltrich, Germany). Detached leaves were darkadapted for 20 min after which the $F_{v} / F_{m}$ parameter was determined using a 1.0-s saturated pulse (PPFD $=3,000$ $\mu \mathrm{mol} \mathrm{m} \mathrm{m}^{-2} \mathrm{~s}^{-1}$ ) provided by a LED-array illumination unit $I M A G-M A X / L(450 \mathrm{~nm})$. The heat-induced changes of $\mathrm{Chl}$ fluorescence parameters were determined at increasing temperature from 25 and to $55^{\circ} \mathrm{C}$. The measurement was started at $25^{\circ} \mathrm{C}$ and when the photosynthesis was steady [after $15 \mathrm{~min}$ at $50 \mu \mathrm{mol}$ (photon) $\mathrm{m}^{-2} \mathrm{~s}^{-1}$ of actinic light on], it was followed by heating the leaves from 25 to $55^{\circ} \mathrm{C}$ at a rate of $1.5^{\circ} \mathrm{C} \mathrm{min}{ }^{-1}$. During the measurements saturated flashes were applied at each ${ }^{\circ} \mathrm{C}$. The quenching parameters were determined according to the nomenclature described by Klughammer and Schreiber (2008).

Measurements of antioxidant enzymes: For the analysis of antioxidant enzyme activity, $0.5 \mathrm{~g}$ leaf tissue was homogenized in $2.5 \mathrm{ml}$ of ice-cold Tris buffer $(0.5 \mathrm{M}, \mathrm{pH} 7.5)$ containing $3 \mathrm{mM} \mathrm{MgCl}$ and $1 \mathrm{mM}$ EDTA. The ascorbate peroxidase (APX; EC 1.11.1.11.) activity was determined in the presence of $0.2 \mathrm{M}$ Tris buffer ( $\mathrm{pH} 7.8$ ) and $5.625 \mathrm{mM}$ ascorbic acid. The reaction was started with $0.042 \% \mathrm{H}_{2} \mathrm{O}_{2}$ (Janda et al. 1999). The decrease in absorbance at $290 \mathrm{~nm}$ was monitored. The catalase (EC 1.11.1.6.) activity of the extract was measured spectrophotometrically by monitoring the decrease in absorbance at $240 \mathrm{~nm}$ according to Janda et al. (1999). The guaiacol peroxidase (G-POD; EC 1.11.1.7.) activity was measured at $470 \mathrm{~nm}$ as described by Ádám et al. (1995). The reaction mixture consisted of $88 \mathrm{mM}$ Na-acetate buffer ( $\mathrm{pH} 5.5), 0.88 \mathrm{mM}$ guaiacol, $0.0375 \% \mathrm{H}_{2} \mathrm{O}_{2}$, and enzyme extract. The glutathione reductase (GR; EC 1.6.4.2.) activity was determined at $412 \mathrm{~nm}$ according to Smith et al. (1988). The reaction mixture contained $75 \mathrm{mM}$ Na-phosphate buffer $(\mathrm{pH} 7.5)$, $0.15 \mathrm{mM}$ diethylenetriaminepentaacetic acid, $0.75 \mathrm{mM}$ 5,5'-dithiobis(2-nitrobenzoic acid), $0.1 \mathrm{mM}$ NADPH, $0.5 \mathrm{mM}$ oxidized glutathione, and $50 \mu \mathrm{l}$ of plant extract in a total volume of $1 \mathrm{ml}$. The glutathione-S-transferase (GST; EC 2.5.1.18.) activity was measured by following changes in the absorbance at $340 \mathrm{~nm}$ in a mixture containing $72.7 \mathrm{mM}$ Na-phosphate buffer $(\mathrm{pH}$ 6.5), 3.6 mM reduced glutathione, $1 \mathrm{mM}$ 1-chloro-2,4-dinitrobenzene, and enzyme extract (Mannervik and Guthenberg 1981). The enzyme activities were determined photometrically with a UV-visible recording spectrophotometer (UV-VIS 160A, Shimadzu Corp., Kyoto, Japan), and expressed in nkatal $\mathrm{g}^{-1}$ (fresh mass, FM).

Polyamine and 1,3-diaminopropane analyses: The analyses of polyamines were carried out as described earlier (Németh et al. 2002) with slight modifications. Leaves of $200 \mathrm{mg}$ were homogenized with $1 \mathrm{ml}$ of 0.2 $\mathrm{M}$ ice-cold perchloric acid and then left for $20 \mathrm{~min}$ on ice. The extract was centrifuged at $10,000 \times g$ for 20 min and the supernatant was used. Putrescine (PUT), spermidine (SPD), and spermine (SPM), together with the catabolite of the latter two ones, 1,3-diaminopropane (DAP), were analysed as dansylated derivatives via HPLC using a W2690 separation module and a W474 scanning fluorescence detector with excitation at $340 \mathrm{~nm}$ and emission at $515 \mathrm{~nm}$ (Waters, Milford, MA, USA). 
Measurements of plant hormones: Analyses of plant hormones were carried out with UHPLC-UniSpray-MS/MS measurements described in detail by Pál et al. (2019). Briefly, five parallel samples of frozen homogeneous plant material (200 mg of FM each) were spiked with $2 \mathrm{ng}$ $\left[{ }^{2} \mathrm{H}_{6}\right](+)$-cis,trans-abscisic acid (OlChemIm, Olomouc, Czech Republic) serving as an internal standard. Afterwards, the samples were extracted two times subsequently with methanol:water $(2: 1, \mathrm{v} / \mathrm{v})$ solution, filtered and submitted for analysis at a final sample concentration of $100 \mathrm{mg}$ (FM extract) $\mathrm{ml}^{-1}$. Separation was achieved with an Acquity I class UPLC system (Waters, Milford, MA, USA) on an Acquity HSS T3 column (1.8 $\mu \mathrm{m}$, $100 \mathrm{~mm} \times 2.1 \mathrm{~mm}$; Waters $)$, kept at $40^{\circ} \mathrm{C}$. Mass spectrometry detection was performed on a Xevo TQ-XS MS/MS system (Waters) equipped with a UniSpray ion source. Where it was applicable, at least three MRM transitions were used for data acquisition and quantitation was carried out on the transition exhibiting the highest signal-to-noise ratio (Table 1S, supplement).

Statistical analysis: Usually five parallel samples were collected for each measurement. Significant differences between the treatments and the genotypes were probed using the $t$-test method.

\section{Results}

Photosynthetic processes: The effects of elevated temperature $\left(30^{\circ} \mathrm{C}\right)$ were characterized by monitoring the Chl contents in the leaves using the SPAD method and by determination of the $\mathrm{F}_{\mathrm{v}} / \mathrm{F}_{\mathrm{m}}$ Chl $a$ fluorescence induction

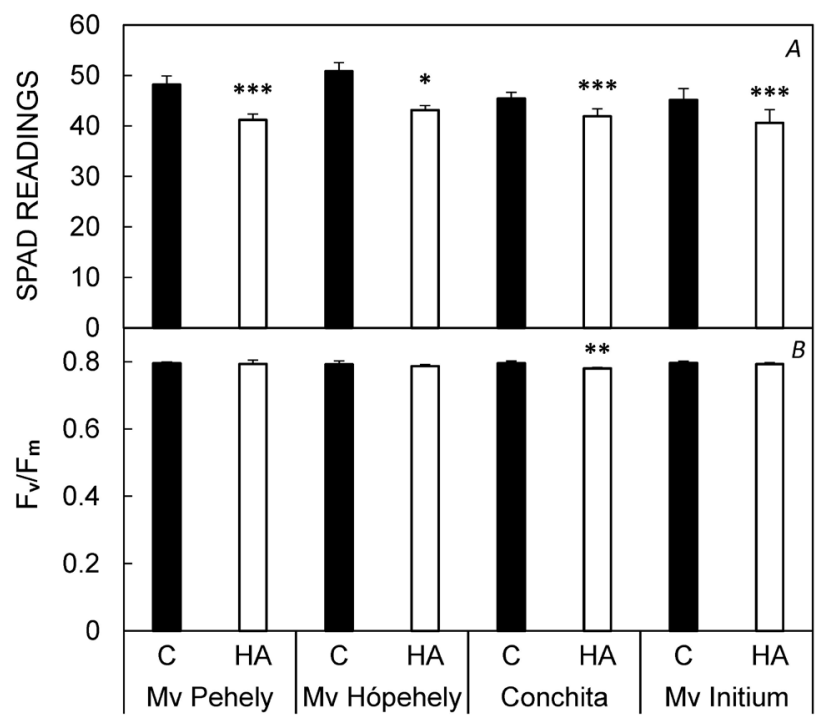

Fig. 1. Chlorophyll content estimated using $\operatorname{SPAD}$ values $(A)$ and $\mathrm{F}_{\mathrm{v}} / \mathrm{F}_{\mathrm{m}}$ parameters $(B)$ in control $\left(\mathrm{C}\right.$; growing at $22 / 20^{\circ} \mathrm{C}$; black bars) and in heat-acclimated (HA; 2 weeks at $30 / 27^{\circ} \mathrm{C}$; white bars) young spring and winter oat ('Mv Pehely' and 'Mv Hópehely') and barley ('Conchita' and 'Mv Initium') varieties. Error bars indicate SD. ${ }^{*},{ }^{* *},{ }^{* * *}$ represent statistically significant differences between $\mathrm{C}$ and $\mathrm{HA}$ values at $p<0.05,0.01$, and 0.001 levels, respectively. parameter representing the maximum quantum efficiency of PSII. Fig. 1 shows that growing at $30^{\circ} \mathrm{C}$ for a week only slightly reduced the Chl content in all the barley and oat genotypes tested in the present experiment. Furthermore, the $\mathrm{F}_{\mathrm{v}} / \mathrm{F}_{\mathrm{m}}$ parameter showed only a slight, but statistically significant decrease in the spring barley cv. 'Conchita'. These results indicate that the applied heat treatment only caused a mild stress in the plants.

Temperature dependence of the Chl $a$ fluorescence induction parameters represents the thermostability of the PSII and can demonstrate the heat acclimation capacity of plants. As it is shown in Fig. $2 A$, the quantum yield of PSII ( $\mathrm{Y}_{\text {(II) }}$ ) progressively decreased above $\mathrm{ca} \cdot 40^{\circ} \mathrm{C}$ (values between $25-40^{\circ} \mathrm{C}$ are presented in Table $2 \mathrm{~S}$, supplement). The decrease started approximately at the same temperature in all genotypes grown at $22^{\circ} \mathrm{C}$, while the decline of $\mathrm{Y}_{\text {(II) }}$ began at higher temperatures in plants, which were growing at $30^{\circ} \mathrm{C}$, than in those grown at $22^{\circ} \mathrm{C}$ (Fig. $2 A$ ). These results indicate an increase in the thermostability of
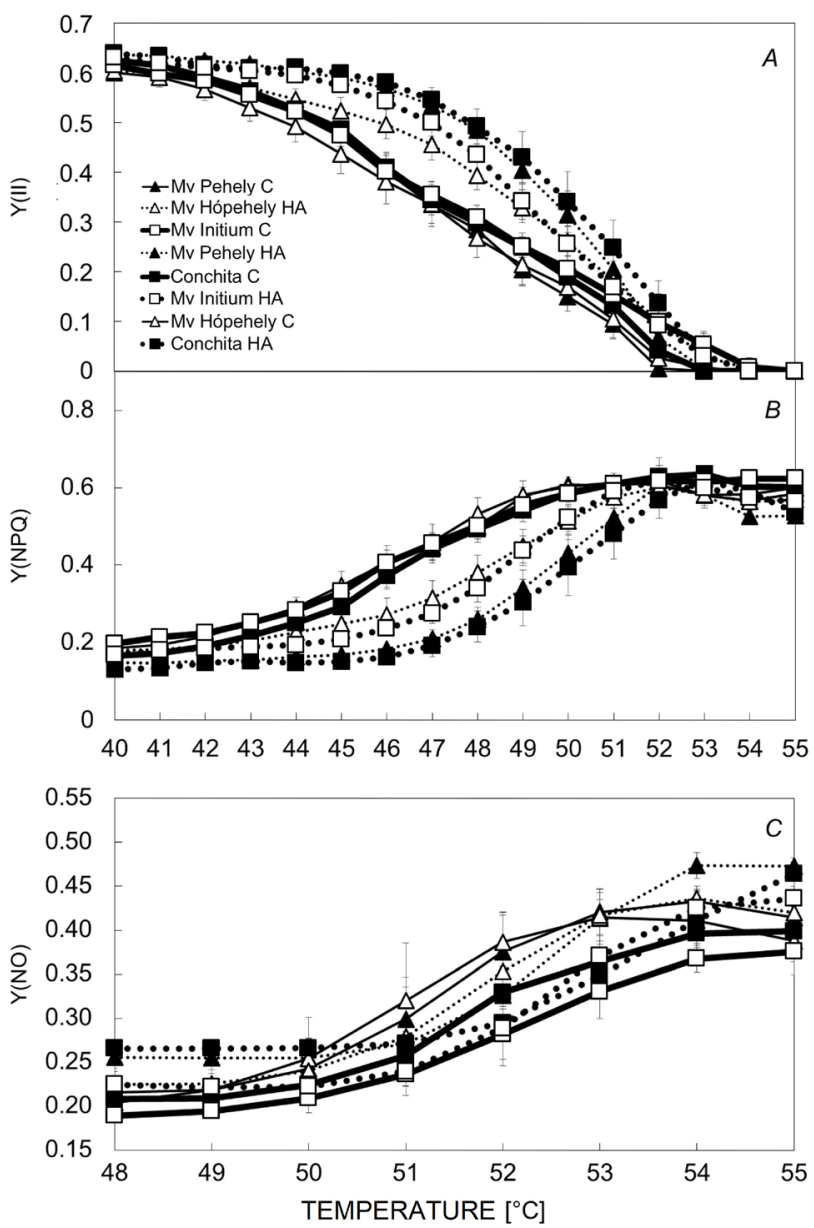

Fig. 2. Temperature dependence of quantum yield of PSII ( $\left.\mathrm{Y}_{\text {(II) }}\right)$ $(A)$, regulated nonphotochemical quenching $\left(\mathrm{Y}_{(\mathrm{NPQ})}\right)(B)$, and nonregulated nonphotochemical quenching $\left(\mathrm{Y}_{(\mathrm{NO})}\right)(C)$ in control $\left(\mathrm{C}\right.$; growing at $22 / 20^{\circ} \mathrm{C}$; solid lines) and in heat-acclimated (HA; 2 weeks at $30 / 27^{\circ} \mathrm{C}$; dotted lines) young spring (filled symbols) and winter (open symbols) oat ('Mv Pehely' and 'Mv Hópehely'; triangles) and barley ('Conchita' and 'Mv Initium'; squares) varieties. Error bars indicate SD. 
the PSII during the heat acclimation. The shift was slightly higher in oat cv. 'Mv Pehely' and in barley cv. 'Conchita' than that in 'Mv Hópehely' or 'Mv Initium', indicating that the heat acclimation may depend on the type of varieties, namely on spring or winter genotypes, but not on the species. Similar to $\mathrm{Y}_{(\mathrm{II})}$, the temperature dependence of $\mathrm{Y}_{(\mathrm{NPQ})}$, representing the regulated heat dissipation of excess excitation energy, was similar in the control plants, but it shifted to higher temperatures in the heat-treated plants (Fig. 2B). The differences between the spring and winter varieties could also be observed in this parameter (Fig. $2 B$ ). Unlike $\mathrm{Y}_{(\mathrm{II})}$ or $\mathrm{Y}_{(\mathrm{NPQ})}$, the differences between the winter and spring genotypes could not be observed in the temperature response of $\mathrm{Y}_{(\mathrm{NO})}$, representing the component of nonphotochemical quenching relating to the nonregulated heat dissipation (Fig. 2C).

Antioxidant enzyme activities: Growing at elevated temperature - depending on the species and the varieties modified the activities of certain antioxidant enzymes (Fig. 3). GR slightly increased in spring barley 'Conchita', but did not change in winter barley 'Mv Initium' and decreased in both oat varieties 'Mv Hópehely' and 'Mv Pehely' (Fig 3A). APX did not change significantly in barley genotypes, but it increased in 'Mv Hópehely' winter and decreased in 'Mv Pehely' spring oat plants (Fig. 3B). Catalase did not change in barley, but it decreased in both oat varieties. G-POD decreased in both barley genotypes and slightly in 'Mv Hópehely' winter oat (Fig. 3D). In contrast to these antioxidant enzymes, the activity of another protective enzyme, GST was significantly higher in the heat-treated plants than that in the controls in all the genotypes tested; and its activity was substantially higher in the oat varieties than that in the barley plants (Fig. 4).

Polyamines: In order to reveal the heat acclimation processes, the changes in the contents of polyamines in the free fraction were also measured after the heat acclimation period. Beside the major polyamines, putrescine (PUT), spermidine (SPD), and spermine (SPM), the amount of the catabolic product of the latter two, 1,3-diaminopropane (DAP), and the content of another diamine, cadaverine synthesised in a different route unlike PUT - were also determined (Figs. 5, 6). The most pronounced differences in the polyamines contents were found between the species (oat or barley), rather than between the spring and winter cultivars within the same species. Thus, in oat grown at $22^{\circ} \mathrm{C}$, high contents of PUT, while low contents of SPD, SPM (Fig. 5A-C), and cadaverine (Fig. 6) were observed. In contrast to this, barley plants showed high amount of SPD, SPM, and cadaverine, while the amount of PUT was low. According to these differences in SPD and SPM observed between the two plant species, the concentration of DAP showed the opposite pattern (Fig. 5D), as the basal level of it was higher in oat, where lower SPD and SPM contents were detected under control conditions. Heat acclimation substantially affected the polyamine concentrations in all the genotypes. Interestingly, it induced a significant decrease in almost all cases, except in cadaverine, where a significant increase was found in the case of 'Conchita' (Fig. 6). In addition, DAP contents showed appropriate changes to the decrease in the concentration of higher polyamines (SPD and SPM) after heat acclimation. In barley varieties, where pronounced decrease of SPD and SPM was found, the DAP content increased remarkably in both genotypes (Fig. 5D).

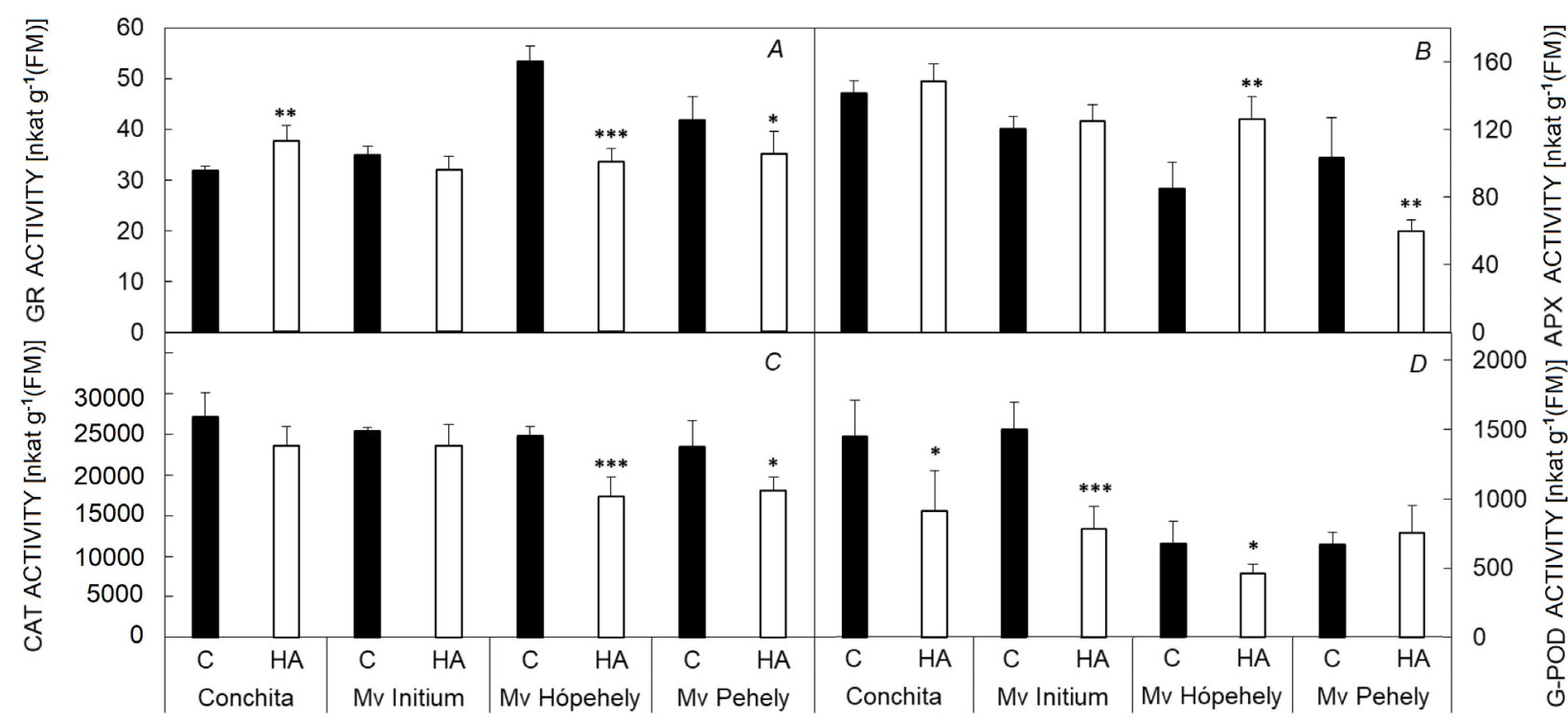

Fig. 3. Activities of antioxidant enzymes, namely glutathione reductase (GR) $(A)$, ascorbate peroxidase (AP) $(B)$, catalase $(\mathrm{CAT})(C)$, and guaiacol peroxidase (G-POD) $(D)$ in control (C; growing at $22 / 20^{\circ} \mathrm{C}$; black bars) and in heat-acclimated $\left(\mathrm{HA} ; 2\right.$ weeks at $30 / 27^{\circ} \mathrm{C}$; white bars) young spring and winter oat ('Mv Pehely' and 'Mv Hópehely') and barley ('Conchita' and 'Mv Initium') varieties. Error bars indicate SD. ${ }^{*},{ }^{* *},{ }^{* * *}$ represent statistically significant differences between $\mathrm{C}$ and HA values at $p<0.05,0.01$, and 0.001 levels, respectively. 


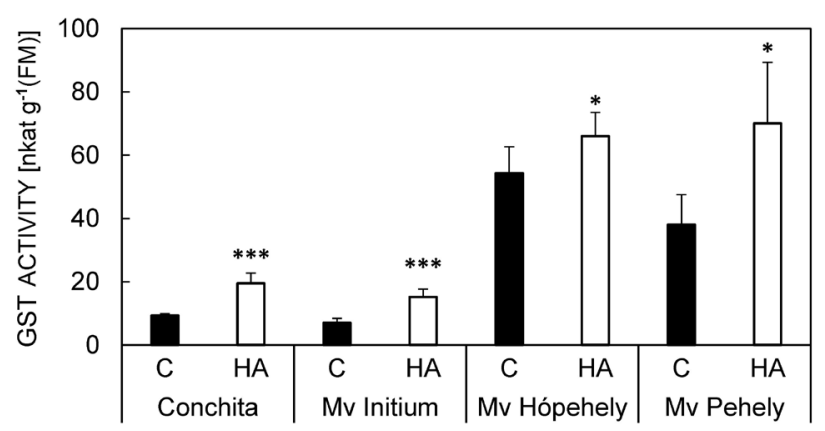

Fig. 4. Activities of glutathione-S-transferase (GST) in control (C; growing at $22 / 20^{\circ} \mathrm{C}$; black bars) and in heat-acclimated (HA; 2 weeks at $30 / 27^{\circ} \mathrm{C}$; white bars) young spring and winter oat ('Mv Pehely' and 'Mv Hópehely') and barley ('Conchita' and 'Mv Initium') varieties. Error bars indicate SD. . and ${ }^{* * *}$ represent statistically significant differences between $\mathrm{C}$ and $\mathrm{HA}$ values at $p<0.05$ and 0.001 levels, respectively.

Hormones: In order to better understand the regulatory mechanisms in barley and oat during the heat acclimation period, the contents of certain plant growth regulators (SA, auxin, and ABA) and some of their related compounds (para-hydroxybenzoic acid, phaseic acid, and dihydrophaseic acid) were also determined. In general, hormone contents varied significantly between the species. Except for SA, all measured hormone contents were higher in barley than that in oat plants under control conditions. Heat treatment significantly increased the free SA concentration in the winter barley 'Mv Initium' and in the oat varieties, but the SA content decreased in the spring barley 'Conchita' (Fig. 7A). While the SA contents were generally lower in the barley varieties than that in the oats, the para-hydroxybenzoic acid content was substantially higher in the barley than that in the oat genotypes. Its concentration was also significantly higher in plants grown at $30^{\circ} \mathrm{C}$ than that in the controls, especially in the barley varieties (Fig. 7B). The concentration of the other plant hormone auxin (IAA), increased only in oat genotypes, where the control values were slightly lower than that in the barley plants (Fig. 7C). The ABA content was the highest in the winter barley 'Mv Initium' and it slightly decreased after heat treatment at $30^{\circ} \mathrm{C}$. In contrast to this, $\mathrm{ABA}$ content was substantially higher in the heat-treated oat genotypes than that in the controls, where the control values were relatively low (Fig. 7D). Phaseic acid is an oxidation product of ABA, while dihydrophaseic acid is created by subsequent conversion of phaseic acid catalysed by a soluble phaseic acid reductase. Both the concentrations of phaseic and dihydrophaseic acid were substantially higher in the barley than that in the oat varieties. Growing at $30^{\circ} \mathrm{C}$ only reduced their content in barley, while in the oat genotypes the effect of heat treatment was not substantial (Fig. $7 E, F)$.

\section{Discussion}

The photosynthetic apparatus including both the $\mathrm{CO}_{2}$ assimilation and the photosynthetic electron transport processes are among the primary targets of thermal damage in plants (Allakhverdiev et al. 2008). However, mild stress often stimulates the protective mechanisms enabling the plants to acclimate to the new environment and eliminate the adverse effect of stress. The mild environmental conditions have been shown having acclimatory effects against a subsequent high temperature stress as presented in wheat plants. However, differences between the winter wheat genotypes in temperature dependence of the fluorescence

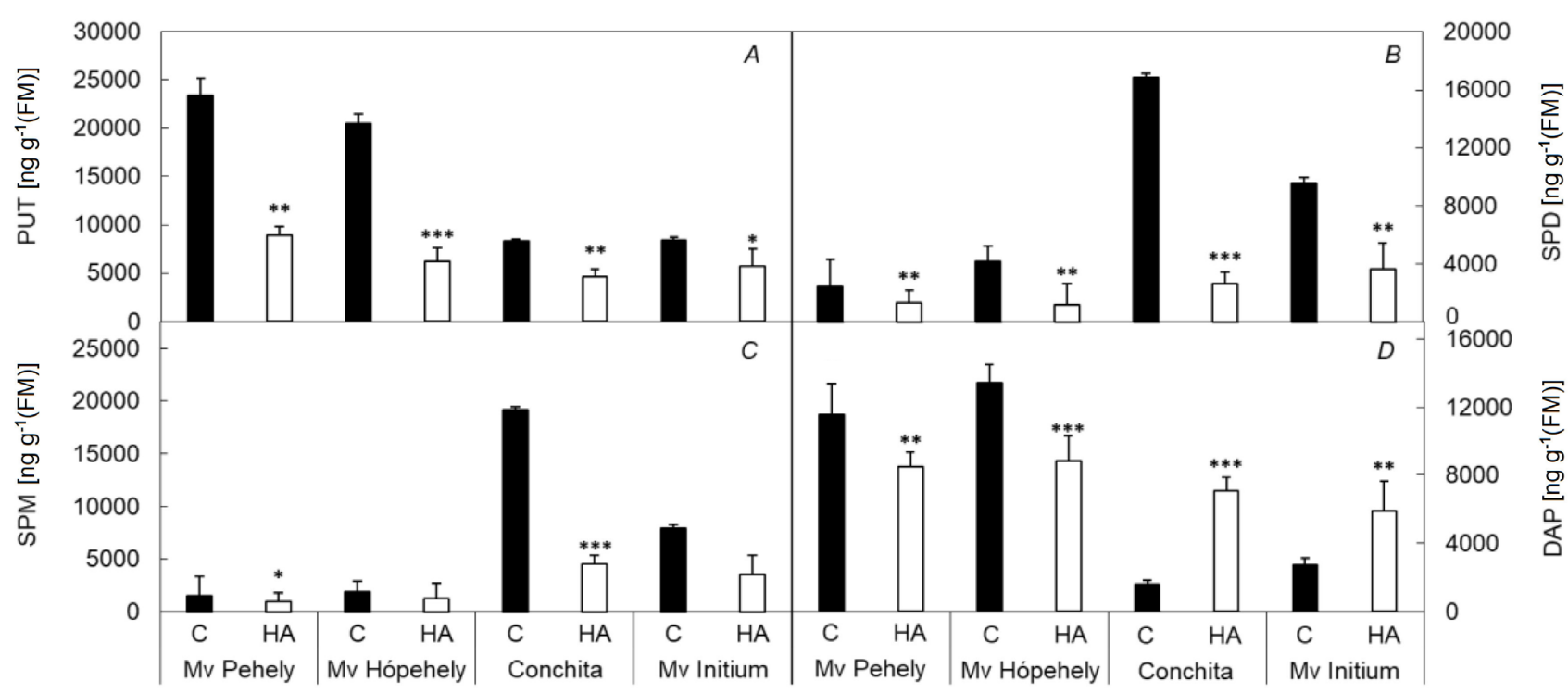

Fig. 5. Contents of major polyamines, namely putrescine (PUT) $(A)$, spermidine (SPD) $(B)$, and spermine (SPM) $(C)$, and the degradation product 1,3-diaminopropane (DAP) $(D)$ in control $\left(\mathrm{C}\right.$; growing at $22 / 20^{\circ} \mathrm{C}$; black bars) and in heat-acclimated $\left(\mathrm{HA} ; 2\right.$ weeks at $30 / 27^{\circ} \mathrm{C}$; white bars) young spring and winter oat ('Mv Pehely' and 'Mv Hópehely') and barley ('Conchita' and 'Mv Initium') varieties. Error bars indicate SD. *, ${ }^{* *},{ }^{* * *}$ represent statistically significant differences between $\mathrm{C}$ and HA values at $p<0.05,0.01$, and 0.001 levels, respectively. 


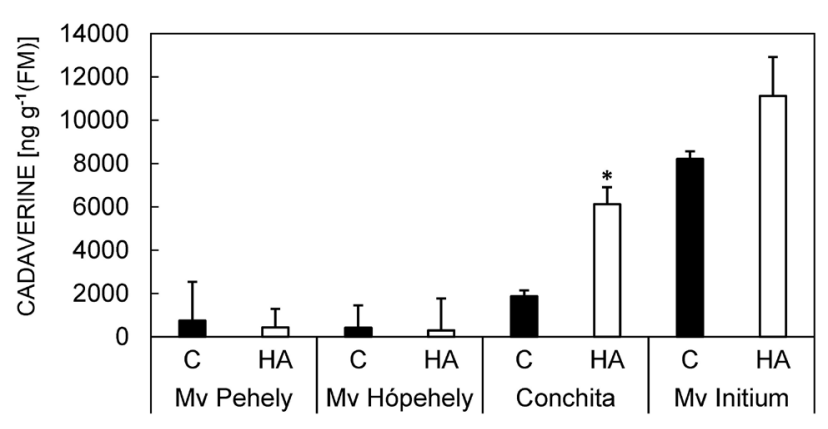

Fig. 6. Cadaverine contents in control (C; growing at $22 / 20^{\circ} \mathrm{C}$; black bars) and in heat-acclimated (HA; 2 weeks at $30 / 27^{\circ} \mathrm{C}$; white bars) young spring and winter oat ('Mv Pehely' and 'Mv Hópehely') and barley ('Conchita' and 'Mv Initium') varieties. Error bars indicate SD. * represents statistically significant differences between $\mathrm{C}$ and HA values at $p<0.05$ level.

induction parameters could not be detected (Végh et al. 2018). In the present experiment, the SPAD and $F_{v} / F_{m}$ values indicated that growing at $30^{\circ} \mathrm{C}$ only caused a mild stress in barley and oat plants. The temperature dependent changes of $\mathrm{Y}_{(\mathrm{II})}$ and $\mathrm{Y}_{(\mathrm{NPQ})}$ represent the thermostability of PSII. Temperature dependence of fluorescence induction parameters also showed that growing at $30^{\circ} \mathrm{C}$ induced heat acclimation of the photosynthetic electron transport system in both barley and oat plants. In agreement with the previous findings, we also found that the heat-induced decreases in $\mathrm{Y}_{(\mathrm{II})}$ and increase in $\mathrm{Y}_{(\mathrm{NPQ})}$ generally started at higher temperatures in the heat-acclimated plants than in the nonacclimated controls, demonstrating the acclimatory effects of mild heat treatment $\left(30^{\circ} \mathrm{C}\right)$. In addition, we also observed in the present study that the slopes of the heat-induced changes in the $\mathrm{Y}_{(\mathrm{II})}$ and $\mathrm{Y}_{(\mathrm{NPQ})}$ fluorescence induction parameters were similar in all genotypes grown at $22^{\circ} \mathrm{C}$ independent of species and genotypes, but differed between the winter and spring cultivars of barley and oat in heat-acclimated plants. However, the generalisation of this observation requires further confirmation with a large number of genotypes.

Heat tolerance is a multifactorial trait, which is determined by various physiological and biochemical mechanisms (Bita and Gerats 2013). In order to better understand the responses of barley and oat plants to a

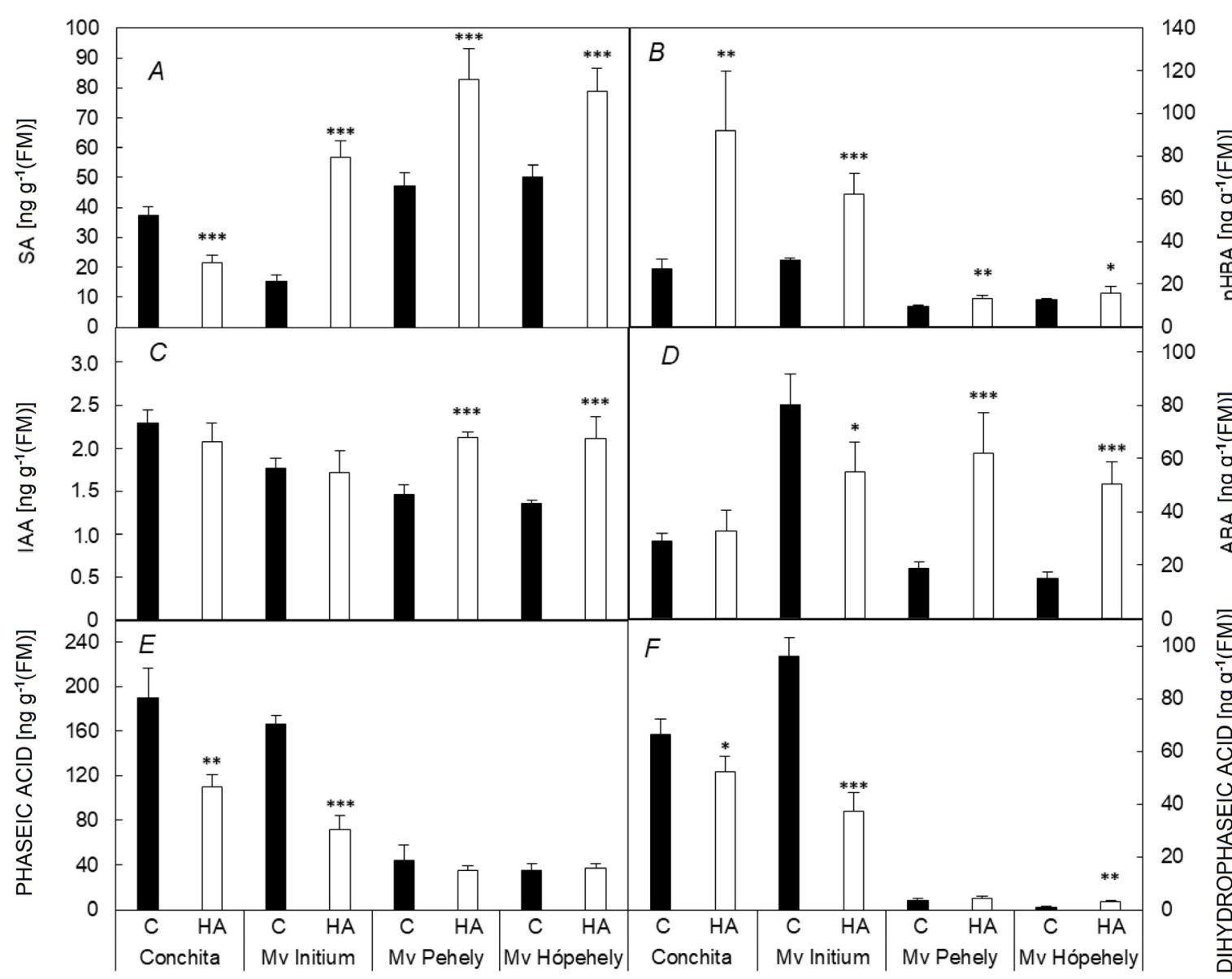

Fig. 7. Salicylic acid (SA) $(A)$, para-hydroxybenzoic acid ( $p$ HBA) $(B)$, indole-3-acetic acid (IAA) $(C)$, abscisic acid (ABA) $(D)$, phaseic acid $(E)$, and dihydrophaseic acid $(F)$ contents in control $\left(\mathrm{C}\right.$; growing at $22 / 20^{\circ} \mathrm{C}$; black bars) and in heat-acclimated (HA; 2 weeks at $30 / 27^{\circ} \mathrm{C}$; white bars) young spring and winter oat ('Mv Pehely' and 'Mv Hópehely') and barley ('Conchita' and 'Mv Initium') varieties. Error bars indicate SD. ${ }^{* * *}{ }^{* * *}$ represent statistically significant differences between C and HA values at $p<0.05,0.01$, and 0.001 levels, respectively. 
moderate, acclimating elevated temperature, we mainly focused on certain antioxidant and hormonal processes in the present study. Induction of the activities of certain antioxidant enzymes has been characterised under various unfavourable environmental conditions, including biotic and abiotic stressors. It has also been described that antioxidant activities under control conditions substantially differ in the different cereal species (Janda et al. 2003). In this experiment, we also found differences between the species regardless of cultivars. It means that the differences were smaller between the winter or spring varieties than that between the species. The winter $\times$ spring type did not matter much, even if it is compared to the effects of heat treatment. Apart from some minor changes, heat acclimation did not substantially modify the activity of the investigated total antioxidant enzyme activities, such as APX, catalase or GR. The most pronounced changes occurred in the G-POD activities. The activity of this enzyme often changes under stress conditions, but for example, in spite of the higher expected oxidative pressure, higher activity was reported at low temperature in the dark than that in the light (Janda et al. 2007). Similarly, in the present study, a lower G-POD activity was detected in some heat-acclimated oat and barley plants - where higher level of stress was assumed - than that in the controls. The explanation for this is still unknown. The induction of the GST during heat treatment was more pronounced than the other antioxidant enzymes, and it was induced in all the genotypes tested. Plant GSTs are enzymes of secondary metabolism. Their roles in catalysing the conjugation and detoxification of certain compounds, such as herbicides, are well known, but their endogenous functions are still poorly understood. Among others, they are involved in responses to oxidative stresses and heavy metal toxicity (Ding et al. 2017), in the synthesis of sulfur-containing secondary metabolites, and the conjugation, transport, and storage of phenolics and flavonoids (Dixon et al. 2010). Since GR, which also utilises glutathione, was not substantially induced after exposure to mild heat stress, it seems that detoxification is more important at elevated temperatures than inducing ROS-scavenging mechanisms.

Polyamines also play role in various cell functions including responses to environmental stresses. Earlier studies suggested a direct relationship between the capacity to enhance the synthesis of polyamines upon exposure to stress and the level of the tolerance (Fariduddin et al. 2013, Minocha et al. 2014). However, some plants accumulate polyamines, others have constant or even lower endogenous polyamine content when exposed to stress. Recent studies support the view that the more polyamine the better theory cannot be generalised (Pál et al. 2017). Under the present experimental conditions, heat treatment significantly reduced the contents of the major polyamines. Although, the degradation product of higher polyamines, DAP also decreased in oat, while it substantially increased in barley plants. The cadaverine content, which is synthesised in a different route, tended to increase in spring barley, 'Conchita', after the heat acclimation period. The most pronounced differences were found depending on the plant species (oat or barley), and not on the growth type (spring or winter cultivars). Similar results were reported in case of the investigation of changes in polyamine content during cold hardening in eight crop genotypes (wheat, barley, and oat), where after cold treatment the polyamine pool pattern was regardless of the growth type (Gondor et al. 2016). The polyamine pool is dynamic, and polyamines also undergo rapid interconversion in the polyamine cycle (Pál et al. 2015). In addition, the content of the individual polyamines may change differently under the same conditions. Investigation on different wheat genotypes revealed that in most cases the PUT content decreased, the SPD increased, while the amount of SPM increased or did not change after heat treatment (Goyal and Asthir 2010). Severe stress conditions may also induce different alteration in the polyamine content compared to a mild stress. In rice, a mild osmotic stress did not influence the PUT content, but severe cold treatment induced high accumulation (Pál et al. 2014). The same osmotic treatment in wheat caused only mild stress and increased PUT, but decreased SPD and SPM content, while in maize resulted in severe stress without influencing the polyamine content (Szalai et al. 2017).

These results suggest that accumulation of the main polyamines does not play a direct role during the heat acclimation in barley and oat plants. However, their signalling effects cannot be excluded, and production of DAP at least in barley plants might also be important via inducing other stress-related protective mechanisms. The involvement of cadaverine is also possible in barley. This polyamine has originally been identified as a lysine decomposition product; but later, its role in plant growth and development, cell signalling, and stress responses had also been reported (Gill and Tuteja 2010, Jancewicz et al. 2016). However, its role in stress responses is controversial and especially in the case of heat acclimation is still hardly documented and poorly understood (Jancewicz et al. 2016).

The interaction between polyamine metabolism and SA signalling has been described (Szalai et al. 2017, Fariduddin et al. 2018). The role of SA under abiotic stress conditions (Khan et al. 2015) and its connection with the photosynthetic processes have also been widely studied (Janda et al. 2014). Exogenous SA may alleviate the damaging effects of abiotic stressors, including, among others, high temperatures (Dat et al. 1998, Larkindale and Knight 2002, Khan et al. 2013). It may also modulate the antioxidant defence system indirectly protecting the photosynthetic machinery. SA may induce genes encoding chaperones, heat shock proteins, or secondary metabolites, and it is also involved in mitogen-activated protein kinase pathway (Chai et al. 2014, Khan et al. 2015). In the present experiment, SA was also induced at elevated temperatures, except in the case of spring barley 'Conchita'. However, the induction of the activities of the antioxidant enzymes was moderate, or in some cases, for example G-POD, it was reduced. Para-hydroxy benzoic acid is one of the major phenolic acids found in many medicinal plants and may serve as antimicrobial agent (Farhan et al. 2017). Similarly to SA, its content was also significantly higher after exposure to heat than that in the controls. Its specific 
role in the heat acclimation processes is still unknown; however, present results suggest that not only the direct SA-related biosynthetic routs are activated during the heat treatment.

SA may also activate auxin synthesis, and it also affects the auxin transport (Pasternak et al. 2019). Therefore the content of IAA was also determined in the leaves. Its control value was similar in both species, and elevated temperature caused an increase only in the oat genotypes, but not in 'Mv Initium', where an increase in the SA content was also detected. So this increase cannot be directly explained by the SA effect. The changes in the other plant hormone, ABA, differed in the two species. While this heat treatment did not change ('Conchita') or reduced ('Mv Initium') the ABA content in barley plants, a substantial increase was observed in the oat varieties. At elevated temperatures, plants may tend to cool their tissues by reducing the ABA content, which is a regulator of stomatal closing. This may explain the reduced ABA content in the leaves during the heat treatment (Dobrá et al. 2015). On the other side, ABA regulates various protective mechanisms, which may contribute to the lower level of heat injury, including mediating the antioxidant capacity, the synthesis of heat shock proteins, or regulating the sugar metabolism signalling (Islam et al. 2018). ABA is also involved in carotenoid biosynthesis (Haisel et al. 2006). It seems, that different genotypes may use the ABArelated processes in different ways. However, the exact role of ABA in the heat acclimation processes and its relationship with other signalling routes still need further research.

Conclusions: Temperature dependence of certain chlorophyll fluorescence induction parameters indicated that growing of winter and spring barley and oat genotypes at $30^{\circ} \mathrm{C}$ increased the heat tolerance of these plants. Using this technique, differences between the spring and winter varieties could also be observed. However, its general confirmation requires further research using higher number of varieties. Results on various stress-related parameters suggested that besides certain similarities in the responses to elevated temperatures, different strategies may operate to avoid the damaging effects of high temperatures in barley and oat plants. It will be necessary to investigate the development of the stressor-acclimating effects of heat treatment as a function of time and other environmental factors (e.g., light). The acclimation of the individual organs and the whole plant may be different, so detailed studies on the role of the root and crown is also required. Responses may also differ at different phenological stages.

\section{References}

Ádám A.L., Bestwick C.S., Barna B., Mansfield J.W.: Enzymes regulating the accumulation of active oxygen species during the hypersensitive reaction of bean to Pseudomonas syringae pv. phaseolicola. - Planta 197: 240-249, 1995.

Allakhverdiev S.I., Kreslavski V.D., Klimov V.V. et al.: Heat stress: An overview of molecular responses in photosynthesis.Photosynth. Res. 98: 541-550, 2008.

Bita C.E., Gerats T.: Plant tolerance to high temperature in a changing environment: Scientific fundamentals and produc- tion of heat stress-tolerant crops. - Front. Plant Sci. 4: 273, 2013.

Chai J., Liu J., Zhou J., Xing D.: Mitogen-activated protein kinase 6 regulates NPR1 gene expression and activation during leaf senescence induced by salicylic acid. - J. Exp. Bot. 65: 65136528, 2014.

Dat J.F., Lopez-Delgado H., Foyer C.H., Scott I.M.: Parallel changes in $\mathrm{H}_{2} \mathrm{O}_{2}$ and catalase during thermotolerance induced by salicylic acid or heat acclimation in mustard seedlings. Plant Physiol. 116: 1351-1357, 1998.

Ding N., Wang A., Zhang X. et al.: Identification and analysis of glutathione S-transferase gene family in sweet potato reveal divergent $G S T$-mediated networks in aboveground and underground tissues in response to abiotic stresses. - BMC Plant Biol. 17: e225, 2017.

Dixon D.P., Skipsey M., Edwards R.: Roles for glutathione transferases in plant secondary metabolism. - Phytochemistry 71: 338-350, 2010.

Dobrá J., Černý M., Štorchová H. et al.: The impact of heat stress targeting on the hormonal and transcriptomic response in Arabidopsis. - Plant Sci. 231: 52-61, 2015.

Farhan A.A.J, Gull M., Rahimuddin S.A. et al.: Antimicrobial activity and biochemical profiling of selected medicinal plants against blood cancer clinical isolates. - Biosci. Biotech. Res. Asia 14: 1277-1284, 2017.

Fariduddin Q., Khan T.A., Yusuf M. et al.: Ameliorative role of salicylic acid and spermidine in the presence of excess salt in Lycopersicon esculentum. - Photosynthetica 56: 750-762, 2018.

Fariduddin Q., Varshney P., Yusuf M., Ahmad A.: Polyamines: potent modulators of plant responses to stress. - J. Plant Interact. 8: 1-16, 2013.

Gill S.S., Tuteja N.: Polyamines and abiotic stress tolerance in plants. - Plant Signal. Behav. 5: 26-33, 2010.

Gondor O.K., Szalai G., Kovács V. et al.: Relationship between polyamines and other cold-induced response mechanisms in different cereal species. - J. Agron. Crop Sci. 202: 217-230, 2016.

Goyal M., Asthir B.: Polyamine catabolism influences antioxidative defense mechanism in shoots and roots of five wheat genotypes under high temperature stress. - Plant Growth Regul. 60: 13-25, 2010.

Haisel D., Pospíšilová J., Synková H. et al.: Effects of abscisic acid or benzyladenine on pigment contents, chlorophyll fluorescence, and chloroplast ultrastructure during water stress and after rehydration. - Photosynthetica 44: 606-614, 2006.

Hernández F., Poverene M., Presotto A.: Heat stress effects on reproductive traits in cultivated and wild sunflower (Helianthus annuus L.): evidence for local adaptation within the wild germplasm. - Euphytica 214: 146, 2018.

Hu L., Xiang L., Zhang L. et al.: The photoprotective role of spermidine in tomato seedlings under salinity-alkalinity stress. - PLoS ONE 9: e110855, 2014.

Islam M.R., Feng B., Chen T., Tao L.: Role of abscisic acid in thermal acclimation of plants. - J. Plant Biol. 61: 255-264, 2018.

Jancewicz A.L., Gibbs N.M., Masson P.H.: Cadaverine's functional role in plant development and environmental response. - Front. Plant Sci. 7: 870, 2016.

Janda T., Gondor O.K., Yordanova R. et al.: Salicylic acid and photosynthesis: signalling and effects. - Acta Physiol. Plant. 36: 2537-2546, 2014.

Janda T., Szalai G., Lesko K. et al.: Factors contributing to enhanced freezing tolerance in wheat during frost hardening in the light. - Phytochemistry 68: 1674-1682, 2007. 
Janda T., Szalai G., Tari I., Páldi E.: Hydroponic treatment with salicylic acid decreases the effects of chilling injury in maize (Zea mays L.) plants. - Planta 208: 175-180, 1999.

Khan M.I.R., Fatma M., Per T.S. et al.: Salicylic acid-induced abiotic stress tolerance and underlying mechanisms in plants. Front. Plant Sci. 6: 462, 2015.

Khan M.I.R., Iqbal N., Masood A. et al.: Salicylic acid alleviates adverse effects of heat stress on photosynthesis through changes in proline production and ethylene formation. - Plant Signal. Behav. 8: e26374, 2013.

Klughammer C., Schreiber U.: Complementary PS II quantum yields calculated from simple fluorescence parameters measured by PAM fluorometry and the Saturation Pulse method. - PAM Application Notes 1: 27-35, 2008.

Larkindale J., Hall J.D., Knight M.R., Vierling E.: Heat stress phenotypes of Arabidopsis mutants implicate multiple signaling pathways in the acquisition of thermotolerance. Plant Physiol. 138: 882-897, 2005.

Larkindale J., Knight M.R.: Protection against heat stressinduced oxidative damage in Arabidopsis involves calcium, abscisic acid, ethylene, and salicylic acid. - Plant Physiol. 128: 682-695, 2002.

Mannervik B., Guthenberg C.: Glutathione transferase (Human placenta). - Method. Enzymol. 77: 231-235, 1981.

Minocha R., Majumdar R., Minocha S.C.: Polyamines and abiotic stress in plants: A complex relationship. - Front. Plant Sci. 5: 175, 2014.

Mostofa M.G., Yoshida N., Fujita M.: Spermidine pretreatment enhances heat tolerance in rice seedlings through modulating antioxidative and glyoxalase systems. - Plant Growth Regul. 73: 31-44, 2014.

Németh M., Janda T., Horváth E. et al.: Exogenous salicylic acid increases polyamine content but may decrease drought tolerance in maize. - Plant Sci. 162: 569-574, 2002.

Ohama N., Sato H., Shinozaki K., Yamaguchi-Shinozaki K.: Transcriptional regulatory network of plant heat stress response. - Trends Plant Sci. 22: 53-65, 2017.

Pál M., Csávás G., Szalai G. et al.: Polyamines may influence phytochelatin synthesis during $\mathrm{Cd}$ stress in rice. - J. Hazard. Mater. 340: 272-280, 2017.

Pál M., Ivanovska B., Oláh T. et al.: Role of polyamines in plant growth regulation of Rht wheat mutants. - Plant Physiol. Bioch. 137: 189-202, 2019.

Pál M., Kovács V., Szalai G. et al.: Salicylic acid and abiotic stress responses in rice. - J. Agron. Crop Sci. 200: 1-11, 2014.

Pál M., Szalai G., Janda T.: Speculation: polyamines are important in abiotic stress signaling. - Plant Sci. 237: 16-23, 2015.

Pál M., Tajti J., Szalai G. et al.: Interaction of polyamines, abscisic acid and proline under osmotic stress in the leaves of wheat plants. - Sci. Rep. 8: 12839, 2018.

Pasternak T., Groot E.P., Kazantsev F. et al.: Salicylic acid affects root meristem patterning via auxin distribution in a concentration-dependent manner. - Plant Physiol. 180: 1725-1739, 2019.

Smith I.K., Vierheller T.L., Thorne C.A.: Assay of glutathione reductase in crude tissue homogenates using 5,5'-dithiobis (2-nitrobenzoic acid). - Anal. Biochem. 175: 408-413, 1988.

Suzuki N., Katano K.: Coordination between ROS regulatory systems and other pathways under heat stress and pathogen attack. - Front. Plant Sci. 9: 490, 2018.

Szalai G., Janda K., Darkó É. et al.: Comparative analysis of polyamine metabolism in wheat and maize plants. - Plant Physiol. Bioch. 112: 239-250, 2017.

Tiburcio A.F., Altabella T., Bitrián M., Alcázar R.: The roles of polyamines during the lifespan of plants: from development to stress. - Planta 240: 1-18, 2014.

Tripathy B.C., Oelmüller R.: Reactive oxygen species generation and signaling in plants. - Plant Signal. Behav. 7: 1621-1633, 2012.

Végh B., Marček T., Karsai I. et al.: Heat acclimation of photosynthesis in wheat genotypes of different origin. - S. Afr. J. Bot. 117: 184-192, 2018.

Volkov R.A., Panchuk I.I., Mullineaux P.M., Schöffl F.: Heat stress-induced $\mathrm{H}_{2} \mathrm{O}_{2}$ is required for effective expression of heat shock genes in Arabidopsis. - Plant Mol. Biol. 61: 733746, 2006.

Xu S., Li J., Zhang X. et al.: Effects of heat acclimation pretreatment on changes of membrane lipid peroxidation, antioxidant metabolites, and ultrastructure of chloroplasts in two cool-season turfgrass species under heat stress. - Environ. Exp. Bot. 56: 274-285, 2006.

(C) The authors. This is an open access article distributed under the terms of the Creative Commons BY-NC-ND Licence. 